\title{
Evaluation of the Effect of Sedation as a Confounding Factor in The Diagnostic Validity of Lumbar Facet Joint Pain: A Prospective, Randomized, Double-Blind, Placebo-Controlled Evaluation
}

Laxmaiah Manchikanti, MD, Kim S. Damron, RN, Jose Rivera, MD, Carla D. McManus, RN, BSN, Sheila D. Jackson, RN, Renee C. Barnhill, RN, and Jennifer C. Martin, RN

Background: Lumbar facet (zygapophysial) joints have been implicated as the source of chronic pain in $15 \%$ to $45 \%$ of patients with chronic low back pain. Diagnosis may be confounded by false-positive results with a single diagnostic block and administration of anxiolytics and narcotics prior to or during the diagnostic facet joint blocks.

Objective: To evaluate the effect of midazolam and fentanyl on the diagnostic validity of of lumbar facet joint pain.

Study Design: Randomized, prospective, double-blind, placebo-controlled evaluation.

Methods: The design consisted of a placebo group receiving sodium chloride solution and two experimental groups receiving either midazolam or fentanyl. The patients included in the study were diagnosed with facet joint pain with controlled comparative local anesthetic blocks of medial branches or L5 dorsal rami. They had been treated with lumbar facet joint nerve blocks with good pain relief, and were presenting for repeat treatment after a period of symptom relief.

The study was undertaken in an interventional pain management practice.

Outcome Measures: Outcomes were assessed at baseline and after the administration of 1 of the 3 solutions (Group I, sodium chloride solution; Group II, midazolam; or Group III, fentanyl).

Outcome measures included numeric pain scale, proportion of pain relief, and ability to perform prior painful movements.

Results: Pain relief of $\geq 80 \%$ was noted in $2 \%$ of the patients in Group I, $5 \%$ of the patients in Group II, and $7 \%$ in Group III. Pain relief of $\geq 50 \%$ was noted in $7 \%$ of the patients in Group I, $5 \%$ of the patients in
Group II, and $13 \%$ of the patients in Group III. There were no significant differences among the groups.

Conclusion: The administration of sedation with midazolam or fentanyl is a confounding factor in the diagnosis of lumbar facet joint pain in patients with chronic low back pain. However, this study suggests that if strict criteria including pain relief and ability to perform prior painful movements is used as the standard for evaluating the effect of controlled local anesthetic blocks, the diagnostic validity of lumbar facet joint nerve blocks may be preserved.

Keywords: Chronic low back pain, lumbar facet joint pain, controlled comparative local anesthetic blocks, false-positives, confounding factors, analgesia
Among chronic pain problems, pain emanating from various structures of the lumbar spine remains a major challenge, despite the efforts extended in gathering information, research, prevention, treatment, and rehabilitation (1). Various structures in the lumbar spine, such as facet joints, intervertebral discs, dorsal root ganglia, muscles, and ligaments, are capable of causing low back pain, and lower extremity pain. Facet joints have

From Pain Management Center of Paducah, Paducah, kentucky.

Address Correspondence: Laxmaiah Manchikanti, MD, 2831 Lone Oak Road, Paducah, Kentucky 42003

Funding: Facilities and funding were provided by Ambulatory Surgery Center and Pain Management Center of Paducah, Paducah, KY 42003

Conflict of Interest: None

Disclaimer: There was no external funding in preparation of this manuscript.

Acknowledgement:

Manuscript received on $7 / 2 / 04$

Revision submitted on $8 / 20 / 04$

Accepted for publication on $9 / 2 / 04$ been increasingly recognized as a significant source of low back and lower extremity pain. Despite the high prevalence of low back pain, it has been suggested that a specific etiology of back pain can be diagnosed in only about $15 \%$ of patients with certainty based on clinical examination alone (2-5).

Bogduk (5) noted that a reductionist approach to chronic low back pain requires an anatomical diagnosis. Bogduk (6) identified four factors necessary for any structure to be deemed a cause of back pain: a nerve supply to the structure; the ability of the structure to cause pain similar to that seen clinically in normal volunteers; the structure's susceptibility to painful diseases or injuries; and demonstration that the structure can be a source of pain in patients using diagnostic techniques of known reliability and validity. In accordance with postulates of Bogduk $(6,7)$, the lumbar facet joints or zygapophysial joints are innervated, they produce pain in normal volunteers, and relief of pain has been demonstrated by using diagnostic techniques of known reliability and validity.

Based on the response to controlled diagnostic blocks of lumbar facet joints, in accordance with the criteria established by the International Association for the Study of Pain (8), the prevalence of lumbar facet joint pain has been shown to range from $15 \%$ to $45 \%$ in patients with chronic low back pain (9-16).

The evidence for lumbar facet joints being a source of chronic low back pain is compelling. Yet, there are no neurophysiologic findings, radiologic findings, physical findings, historical or clinical features that are either clearly indicative or diagnostic of lumbar facet joint pain (2-7, 17, 18). Consequently, it has been postulated that the blocks of the facet or zygapophysial joint can be performed in order to test the hypothesis that the target joint is the source of the patient's pain.

True-positive responses may be secured by performing controlled blocks, 
either in the form of placebo injections of normal saline or comparative local anesthetic blocks, in which the same joint is anesthetized on two separate occasions, but using local anesthetics with different durations of action. The specificity of lumbar medial branch blocks as well as the ability of lumbar medial branch blocks to anesthetize facet joints has been demonstrated $(19,20)$. However, with single local anesthetic blocks, a significant proportion of patients ( $22 \%$ to $41 \%$ ) may present with false-positive results (11-16, 21).

Face validity and construct validity of facet joint blocks has been well established (18-20, 22). However, multiple other confounding factors may affect the diagnostic validity of lumbar facet joint blocks. These factors include psychological and behavioral status, as well as administration of anxiolytics, narcotics, and other agents. The issue of confounding factors has been well investigated in provocation discography (23-26). A lack of influence of psychological factors on the validity of controlled comparative diagnostic local anesthetic blocks of facet joints in the low back has been demonstrated (27). A lack of value of provocation was also demonstrated with lumbar zygapophysial joints (28). However, the effects of anxiolytics and narcotics on the validity of diagnosis of lumbar facet joint pain by means of controlled comparative local anesthetic blocks have not been studied.

This evaluation was conducted to evaluate the effect of midazolam and fentanyl on the validity of diagnosis of lumbar facet joint pain. Patients who were proven to have lumbar facet joint pain, demonstrated by fluoroscopically directed controlled comparative local anesthetic blocks of medial branches or L5 dorsal rami and therapeutic measures involving lumbar facet joint nerve blocks with good response, but returning for a repeat treatment after a significant period of symptom relief, were included to evaluate the effect of placebo, midazolam, and fentanyl.

\section{Methods}

The protocol was approved by the Institutional Review Board. The design consisted of a control group (Group I ) receiving sodium chloride solution, Group II receiving midazolam, and Group III receiving fentanyl .

The study was undertaken in an in- terventional pain management practice (a specialty referral center) in a private practice setting.

\section{Informed Consent}

All patients were provided with the approved protocol and informed consent document approved by the Institutional Review Board for this study. The informed consent document described the details of the trial.

\section{Inclusion and Exclusion Criteria}

Patients for the study were identified and recruited from the existing patients of the interventional pain management practice. All the patients had a proven diagnosis of lumbar facet joint pain by controlled comparative local anesthetic blocks of medial branches or L5 dorsal rami, and good response to therapeutic Lumbar facet joint nerve blocks.

\section{Inclusion Criteria}

Inclusion criteria consisted of the following:

1. Patients with a history of chronic, function limiting, low back pain of at least two years duration.

2. Patients between ages of 18 and 90 years.

3. Patients with facet joint pain confirmed by controlled, comparative local anesthetic blocks of medial branches or L5 dorsal rami.

4. Patients were treated in the past with lumbar facet joint nerve blocks and were presenting for repeat treatment after a significant period of symptom relief.

5. Patients with the ability to understand the investigation, and/or cooperate with the investigational procedures.

6. Patients with a willingness to participate in the clinical trial.

\section{Exclusion Criteria}

Exclusion criteria were as follows:

1. Patients without confirmed evidence of lumbar facet joint pain.

2. Patients with uncontrolled major depression or other psychiatric disorders.

3. Patient who were pregnant or lactating

4. Patients with multiple complaints involving other problems which have overlapping pain complaints
5. Patients unable to achieve appropriate positioning.

6. Patients unable to understand informed consent and protocol.

7. Patients with history of adverse reactions to either midazolam or fentanyl.

8. Patients who were not willing to participate in the study.

\section{Evaluation}

Evaluation of all the patients included in the study consisted of the following:

1. Demographic data.

2. Routine physical and medical evaluation.

3. Confirmed evidence of lumbar facet joint pain by controlled comparative local anesthetic blocks of medial branches or L5 dorsal rami.

4. Significant symptom relief following lumbar facet joint nerve blocks and necessity for repeat treatment.

5. Pain assessment by numeric pain scale.

6. Identification of painful movements.

\section{Study Design and Investigation}

All the patients in the three groups were provided identical preparation, along with administration of identical volumes of drugs in unlabeled syringes. The study was performed in the holding area of the ambulatory surgery center by registered nurses experienced with evaluation, administration and monitoring of sedatives and narcotics.

After the patients have agreed to participate in the study, patients in all three groups were brought to the holding area of the surgery center. They were allocated into one of the three groups based upon a computer generated randomization scheme with 5 of 15 patients to each group. Pre-drug administration evaluation included determination of baseline pain on a numeric pain rating scale of 0 to 10 , with 0 being no pain and 10 being the worst possible pain such as pain of delivery or a kidney stone in women, or a kidney stone in men. The evaluation also included identification of the painful movements.

Each patient, based on the randomization, received 1 of the 3 solutions in incremental doses of $1 \mathrm{~mL}$ with a maximum of $5 \mathrm{~mL}$ of $\mathrm{NaCl}$ in Group I, $1 \mathrm{mg}$ of midazolam per $\mathrm{mL}$ ( $5 \mathrm{mg}$ per $5 \mathrm{~mL}$ ) in Group II, or $50 \mathrm{mcg}$ of fentanyl per $\mathrm{mL}(250 \mathrm{mcg}$ per $5 \mathrm{~mL}$ ) in Group III. Patient and inves- 


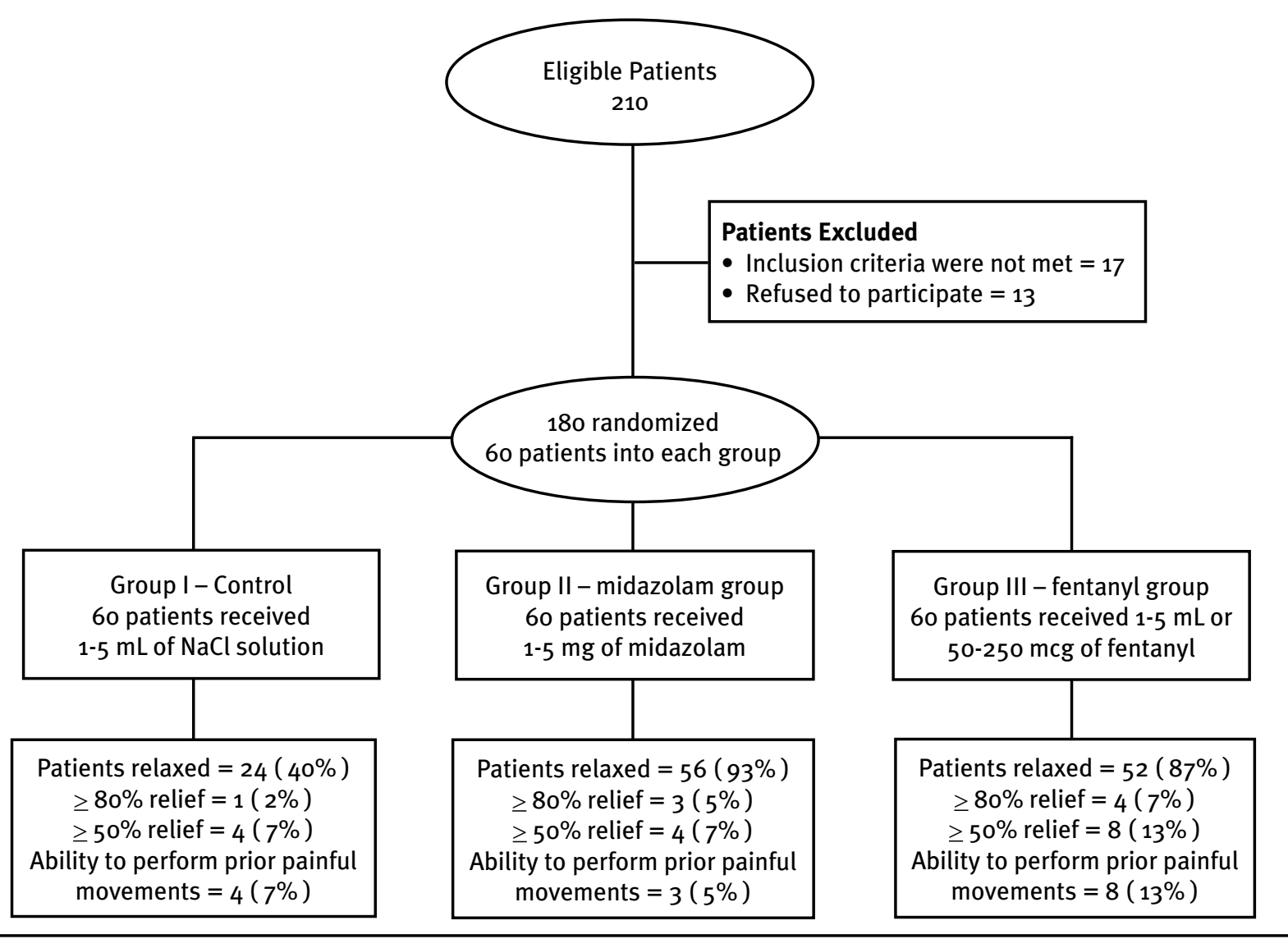

Fig 1. Schematic description of patient flow during the trial

tigator were blinded to the randomized al- ful movements.

location, as well as solution administered, in each and every case.

The solutions were administered slowly based on patient's response with relaxation and/or feeling of drowsiness or until the entire syringe of $5 \mathrm{~mL}$ was administered.

Once the patients expressed either drowsiness or relaxation or the maximum dose was administered, assessment of pain on numeric pain scale and ability to perform pre-sedation painful movements were reassessed.

After completion of the evaluation, unblinding was carried out and the amount of sedation administered in Groups II and III were noted on the record.

\section{Outcomes Assessment}

Outcomes were assessed at baseline prior to the administration of the solution and after the administration of the solution. Multiple parameters included numeric pain scale, proportion of pain relief, and ability to perform prior pain-

\section{Statistical Methods}

Differences in proportions were tested using Chi-Squared test. For comparison of means, one-way analysis of variance was used. After significance was found, the least significant difference (LSD) pairwise multiple comparison test was used to test the difference between means. Results were considered statistically significant if the $P$ value was less than 0.05 . Confidence intervals ( $95 \% \mathrm{CI})$ and

Table 1. Demographic characteristics

\begin{tabular}{|c|c|c|c|c|}
\hline & & $\begin{array}{l}\text { Group I } \\
\text { (Control) }\end{array}$ & $\begin{array}{c}\text { Group II } \\
\text { (Midazolam) }\end{array}$ & $\begin{array}{l}\text { Group III } \\
\text { (Fentanyl) }\end{array}$ \\
\hline \multirow{2}{*}{ Gender } & Male & $35 \%(21)$ & $37 \%(22)$ & $37 \%(22)$ \\
\hline & Female & $65 \%(39)$ & $63 \%(38)$ & $63 \%(38)$ \\
\hline \multirow{2}{*}{ Age (yrs) } & Range & $25-77$ & $25-77$ & $22-83$ \\
\hline & Mean \pm SD & $48 \pm 11.9$ & $48 \pm 11.7$ & $48 \pm 14.5$ \\
\hline Height (inches) & Mean \pm SD & $66 \pm 4.1$ & $66 \pm 3.8$ & $66 \pm 3.8$ \\
\hline Weight (lbs) & Mean \pm SD & $181 \pm 54.2$ & $181 \pm 50.2$ & $184 \pm 43.4$ \\
\hline \multicolumn{2}{|l|}{ Post Surgery } & $25 \%(15)$ & $18 \%(11)$ & $27 \%(16)$ \\
\hline
\end{tabular}

levels (95\% CL) were calculated for proportions and means.

\section{RESULTS}

The study was performed over a period of five months extending from February through June of 2004. Patient flow is depicted in Figure 1. From a sample of 210 eligible patients, 180 were randomized with 60 patients in each group.

\section{Demographic Characteristics}

Table 1 illustrates the demograph- 
Table 2. Characteristics of administration of drugs and their effect

\begin{tabular}{|c|c|c|c|c|c|}
\hline & & $\begin{array}{l}\text { Group I } \\
\text { (Control) }\end{array}$ & $\begin{array}{c}\text { Group II } \\
\text { (Midazolam) }\end{array}$ & $\begin{array}{l}\text { Group III } \\
\text { (Fentanyl) }\end{array}$ & $P$ Value \\
\hline \multirow{2}{*}{$\begin{array}{l}\text { Time required } \\
\text { for relaxation } \\
\text { (in minutes) }\end{array}$} & Mean \pm SD & $8.7 \pm 2.9$ & $8.6 \pm 2.9$ & $8.8 \pm 3.0$ & 0.942 \\
\hline & Range & $4-20$ & $4-15$ & $3-16$ & \\
\hline \multirow{6}{*}{$\begin{array}{l}\text { Amount of } \\
\text { solution or } \\
\text { drug dosage } \\
\text { (in } \mathrm{ml} \text { ) }\end{array}$} & $1 \mathrm{ml}$ & $1 \%(1)$ & - & $1 \%(1)$ & \multirow{5}{*}{0.000} \\
\hline & $2 \mathrm{ml}$ & $12 \%(7)$ & $30 \%(18)$ & $25 \%(15)$ & \\
\hline & $3 \mathrm{ml}$ & $12 \%(7)$ & $28 \%(17)$ & $42 \%(25)$ & \\
\hline & $4 \mathrm{ml}$ & $10 \%(6)$ & $19 \%(11)$ & $13 \%(8)$ & \\
\hline & $5 \mathrm{ml}$ & $65 \%(39)$ & $23 \%(14)$ & $19 \%(11)$ & \\
\hline & Mean \pm SD & $4 \cdot 3 \pm 1.2$ & $3.4 \pm 1.2$ & $3.2^{\star} \pm 1.1$ & 0.000 \\
\hline \multicolumn{2}{|l|}{ Relaxed Status } & $40 \%(24)$ & $93 \% *(56)$ & $87 \% *(52)$ & 0.000 \\
\hline \multicolumn{2}{|c|}{$95 \%$ Confidence Interval } & $28 \%-52 \%$ & $87 \%-99 \%$ & $79 \%-96 \%$ & \\
\hline
\end{tabular}

* Indicates significant difference with Group I

ic characteristics of patients included in the study. No significant differences were noted with regards to gender, age, height, weight, and history of previous surgery.

\section{Study Characteristics}

Details with regards to time required for relaxation, amount of solution or drug in dosage, and relaxed status are illustrated in Table 2. There were no significant differences noted in the time required for

\section{Pain Relief}

Descriptions of pain measurements prior to and after the administration of appropriate drugs or sodium chloride solution are illustrated in Table 3. There were no differences noted in the baseline or post-study follow-up pain levels among the groups. The proportion of patients receiving significant relief ( $\geq 80 \%$ or $\geq 50 \%$ relief was similar in all three groups.

Description of pain relief and correlation with ability to perform movements painful prior to injection of solution are illustrated in Table 4. There were no significant differences noted either in the proportion of relief or ability to perform previously painful movements. Figures 2 and 3 illustrate the proportion of patients with pain relief and ability to perform baseline painful movements in poststudy follow-up period in each group.

tion or drug dosage was significantly in Group III compared to Group I.

Relaxation status varied in all three groups. Group II, receiving midazolam, had the greatest proportion of patients relaxed with 93\%, whereas Group III had $87 \%$ of the patients. Both groups significantly differed from Group I with only $40 \%$ of the patients relaxed.

\section{Complications}

There were no adverse events or complications during the study.

\section{Discussion}

In this randomized, placebo-controlled, double-blind evaluation, we

Table 3. Comparison of pain status by numeric pain scales

\begin{tabular}{|l|l|c|c|c|c|}
\hline \multicolumn{2}{|l|}{ Numeric Pain Scale } & $\begin{array}{c}\text { Group I } \\
\text { (Control) }\end{array}$ & $\begin{array}{c}\text { Group II } \\
\text { (Midazolam) }\end{array}$ & $\begin{array}{c}\text { Group III } \\
\text { (Fentanyl) }\end{array}$ & PValue \\
\hline Baseline pain scale & Mean \pm SD & $7.6 \pm 1.5$ & $7.4 \pm 1.7$ & $7.5 \pm 1.8$ & 0.834 \\
\hline Post-study follow-up & Mean \pm SD & $6.6 \pm 1.8$ & $6.2 \pm 2.2$ & $6.0 \pm 2.4$ & 0.301 \\
\hline Change on pain scale & Mean \pm SD & $1.0 \pm 1.5$ & $1.3 \pm 1.5$ & $1.5 \pm 2.0$ & 0.226 \\
\hline Significant relief ( $\geq \mathbf{8 0} \%$ relief) & $2 \%(1)$ & $5 \%(3)$ & $7 \%(4)$ & 0.400 \\
\hline Significant relief ( $\geq \mathbf{5 0} \%$ relief) & $7 \%(4)$ & $5 \%(3)$ & $13 \%(8)$ & 0.272 \\
\hline
\end{tabular}

Table 4. Proportion of pain relief and ability to perform movements painful prior to injection of solution

\begin{tabular}{|c|c|c|c|c|c|c|}
\hline \multirow[b]{2}{*}{ Percent Relief } & \multicolumn{2}{|c|}{$\begin{array}{l}\text { Group I } \\
\text { (Control) }\end{array}$} & \multicolumn{2}{|c|}{$\begin{array}{c}\text { Group II } \\
\text { (Midazolam) }\end{array}$} & \multicolumn{2}{|c|}{$\begin{array}{c}\text { Group III } \\
\text { (Fentanyl) }\end{array}$} \\
\hline & $\begin{array}{c}\text { Number of } \\
\text { patients }\end{array}$ & $\begin{array}{c}\text { Ability to perform } \\
\text { previously } \\
\text { painful } \\
\text { movements }\end{array}$ & $\begin{array}{c}\text { Number of } \\
\text { patients }\end{array}$ & $\begin{array}{l}\text { Ability to perform } \\
\text { previously } \\
\text { painful } \\
\text { movements }\end{array}$ & $\begin{array}{l}\text { Number of } \\
\text { patients }\end{array}$ & $\begin{array}{l}\text { Ability to perform } \\
\text { previously } \\
\text { painful } \\
\text { movements }\end{array}$ \\
\hline $100 \%$ & 0 & 0 & 2 & 2 & 2 & 2 \\
\hline $90 \%$ & 0 & 0 & 0 & 0 & 0 & 0 \\
\hline $80 \%$ & 1 & 1 & 1 & 1 & 2 & 2 \\
\hline $70 \%$ & 1 & 1 & 0 & 0 & 2 & 2 \\
\hline $60 \%$ & 0 & 0 & 0 & 0 & 0 & 0 \\
\hline $50 \%$ & 2 & 2 & 0 & 0 & 2 & 2 \\
\hline$<50 \%$ & 56 & 0 & 57 & 0 & 52 & 0 \\
\hline Total & 60 & 4 & 60 & 3 & 60 & 8 \\
\hline
\end{tabular}




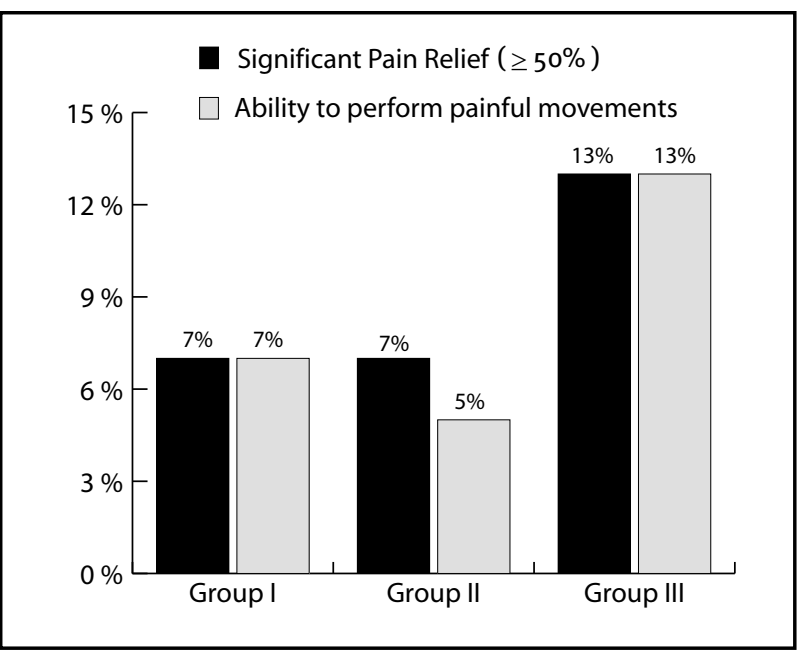

Fig 2. Illustration of significant pain relief ( $\geq 50 \%)$ and ability to perform baseline painful movements in poststudy follow-up period in each group

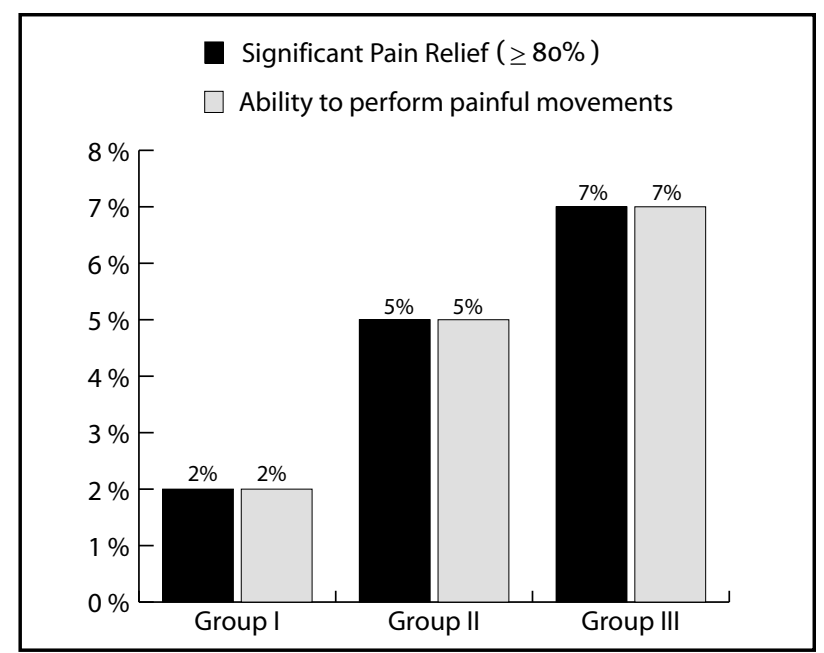

Fig 3. Illustration of significant pain relief ( $\geq 80 \%)$ and ability to perform baseline painful movements in poststudy follow-up period in each group demonstrated that an insignificant proportion of patients with $2 \%$ in Group I (placebo group - $\mathrm{NaCl}$ solution), $5 \%$ in Group II (midazolam group), and 7\% in Group III (fentanyl group) had experienced $\geq 80 \%$ pain relief and were able to perform movements painful prior to the administration of intravenous sodium chloride, midazolam, or fentanyl in patients with chronic low back pain of lumbar facet joint origin. Further, evaluation of significant relief of $\geq 50 \%$ relief with ability to perform baseline painful movements in post follow-up period was seen in $7 \%, 5 \%$, and $13 \%$ of the patients in Groups I, II, and III. Significant differences were only noted with regards to the relaxation status with $40 \%$ in Group I, $93 \%$ in Group II, and $87 \%$ in Group III. This study showed no significant differences between the pain relief, and ability to perform painful movements in any of the groups.

These observations represent progress in the understanding of confounding factors in the diagnosis of lumbar facet joint pain. Based on the results of this study, an insignificant proportion of patients in all the three groups were able to report significant pain relief or had ability to perform movements which were painful prior to administration of solution. The only significant improvement was seen in the relaxation status in patients receiving sedation compared to placebo. Surprisingly, $40 \%$ of the patients in placebo group also were relaxed.

An intravenous preoperative seda- tive dose of an anxiolytic such as midazolam or a short-acting narcotic such as fentanyl is no more likely to cause a patient to report false-positive pain relief with active motion testing than placebo. This proportion is smaller when the criterion standard of $\geq 80 \%$ pain relief and ability to perform painful movements is utilized instead of significant pain relief of $\geq 50 \%$ with ability to perform painful movements. Since fentanyl is administered only in patients who are not relaxed and potentially combative, it appears that most patients who receive fentanyl may not be impacted adversely by diluting the diagnostic value of controlled comparative local anesthetic blocks.

Among the various drugs utilized for anxiolysis and analgesia during interventional procedures, midazolam and fentanyl are common. Midazolam is a short-acting benzodiazepine affecting the central nervous system depressant activities. The effects of midazolam on the central nervous system are dependent on the dose administered, the route of administration, and the presence or absence of other medications.

Fentanyl is a narcotic analgesic. The principle actions of fentanyl are analgesia and sedation. The onset of action of fentanyl is almost immediate when the drug is given intravenously.

The results of this study confirm that some patients obtain relaxation and pain relief with ability to perform prior painful movements with sodium chloride solution, midazolam, and fentanyl.
However, this appears to be in an insignificant proportion of patients whether they are receiving sodium chloride solution, midazolam, or fentanyl, specifically if one considers as the criterion standard of $\geq 80 \%$ relief with ability to perform previously painful movements. Thus, administration of sedation either with midazolam or fentanyl to achieve a relaxed status appears to be safe, with minimal effect on the diagnostic validity of lumbar facet joint nerve blocks.

This evaluation has some potential drawbacks and consequently, may be criticized. First, there was no additional group with combined midazolam and fentanyl. Second, it may be argued that inclusion criteria were flawed as sedation was given to patients after the diagnosis of facet joint pain was already established. Third, it may be argued that we retrospectively inferred the validity of the primary diagnosis. Fourth, the study may be criticized for conducting the evaluation in patients already exposed to the drugs utilized in the study.

First, the study was placebo-controlled, randomized, double-blind, with 60 patients in the each group, with appropriate evaluation of outcome parameters of pain relief and ability to perform prior painful movements. The question about an additional group with midazolam and fentanyl appears to be clinically important. However, the Institutional Review board felt that the administration of the two drugs in a safe manner would be extremely difficult, specifically limiting the 
total dosage to $5 \mathrm{~mL}$ with $50 \%$ midazolam and $50 \%$ fentanyl. Since the drugs cannot be mixed reliably and uniformly, they may have to be provided in two separate syringes. Such a scenario will not provide a double blind evaluation. Consequently, the combined effect of midazolam with fentanyl was not evaluated.

The second issue relates to the inclusion criteria. We employed strict inclusion criteria, with history of chronic, function limiting, low back pain of at least two years of duration, prior confirmed evidence of facet joint pain by controlled comparative local anesthetic blocks. Consequently, all the patients included in the study were treated in the past and were presenting for repeat treatment after a period of symptom relief.

The third question is related to the inference of the validity of the primary diagnosis retrospectively rather than the evaluation of the effect of sedation while performing the primary diagnostic blocks. The effect of sedation was used to evaluate the validity of diagnosis thus, it is not a retrospective study. Thus, the methodology used in this study appeared to be ideal. However, one may argue that to answer this question, this study would have needed to actually give the sedation prior to the controlled comparative local anesthetic blocks performed for the purpose of diagnosis. We believe that such a study will not offer any additional information and could introduce further confounding factors.

Fourth, the study was conducted in patients who were previously exposed to the study drugs. One may argue that the tolerance and the response may confound the results. We do acknowledge that patients do develop tolerance and the response may be attenuated in patients with prior exposure. However, in interventional pain management settings, this situation would be difficult to avoid as most patients have already been exposed to opioids and benzodiazepines prior to presenting for evaluation. Thus, we do not believe that tolerance and a history of exposure to the drugs would have altered the results. Due to randomization, we believe that there should not be any difference among the groups. This study also showed that $65 \%$ of the patients in Group I, 23\% of the patients in Group II, and $19 \%$ of the patients in Group III received $5 \mathrm{~mL}$ (the total dosage) to achieve a relaxed status. Others, even though they were aware that they could receive the maximum dosage or additional medication, felt they were relaxed, and no further drug was administered. Thus, tolerance, if any, did not appears clinically significant.

However, we do acknowledge the limitations of this study. The results of this evaluation should not be generalized. They can only be utilized when the controlled comparative local anesthetic blocks are performed under strict criteria with $0.5 \mathrm{~mL}$ of anesthetic for each nerve, under fluoroscopic visualization, along with application of strict criteria of significant pain relief with ability to perform movements which were painful prior to administration of sedation.

\section{ConcLusion}

This placebo-controlled, doubleblind evaluation showed that the administration of sedation with midazolam or fentanyl could be a confounding factor in the diagnosis of lumbar facet joint pain in patients with chronic low back pain, nevertheless, in a small proportion of patients. This study shows that an intravenous preoperative sedative dose of a narcotic such as fentanyl or an anxiolytic such as midazolam is no more likely to cause a small proportion of patients to report false positive pain relief with active motion testing than sodium chloride placebo. This study suggests that the prudent administration of midazolam and fentanyl to patients who are not relaxed, may not have any significant adverse effect on the diagnostic validity of controlled comparative local anesthetic blocks.

\section{ACKNOWLEDgments}

The authors wish to thank Tonie Hatton and Chandra Sekhar Edam for their assistance in preparation of this manuscript.

The authors also wish to acknowledge the appreciation for peer review process and editorial assistance.

\author{
Author Affiliation \\ Laxmaiah Manchikanti, MD \\ Medical Director \\ Pain Management Center of \\ Paducah \\ Assistant Clinical Professor of \\ Anesthesiology and Perioperative \\ Medicine \\ University of Louisville, KY \\ 2831 Lone Oak Road \\ Paducah, Kentucky 42003 \\ E-mail: drm@apex.net
}

\section{Kim S. Damron, RN}

Nursing Administrator

Ambulatory Surgery Center

2831 Lone Oak Road

Paducah, Kentucky 42003

E-mail:kim@thepainmd.com

Jose J. Rivera, MD

Interventional Pain Physician

Pain Management Center of

Paducah

Ambulatory Surgery Center

2831 Lone Oak Road

Paducah, Kentucky 42003

E-mail: jose@thepainmd.com

Carla D. McManus, RN, BSN

Assistant Nursing Administrator Ambulatory Surgery Center

2831 Lone Oak Road

Paducah, Kentucky 42003

E-mail: carla@thepainmd.com

\section{Sheila D. Jackson, RN}

Clinical Coordinator

2831 Lone Oak Road

Paducah, Kentucky 42003

E-mail: sheila@thepainmd.com

\section{Renee C. Barnhill, RN}

Clinical Coordinator

Ambulatory Surgery Center

2831 Lone Oak Road

Paducah, Kentucky 42003

E-mail: renee@thepainmd.com

Jennifer C. Martin, RN

Clinical Coordinator

Ambulatory Surgery Center

2831 Lone Oak Road

Paducah, Kentucky 42003

E-mail: jennifer@thepainmd.com 


\section{REFERENCES}

1. Hellsing AL, Bryngelsson IL. Predictors of musculoskeletal pain in men: A twentyyear follow-up from examination at enlistment. Spine 2000; 25:3080-3086.

2. Deyo RA, Weinstein JN. Low back pain. N Engl I Med 2001, 344:363-370.

3. Deyo RA, Rainville J, Kent DL. What can the history and physical examination tell us about low back pain? JAMA 1992, 268: 760-765.

4. Bogduk N, McGuirk B. Causes and sources of chronic low back pain. In Bogduk N, McGuirk B (eds.) Medical Management of Acute and Chronic Low Back pain. An Evidence-Based Approach: Pain Research and Clinical Management, Vol 13. Elsevier Science BV; Amsterdam, 2002, pp 115126.

5. Bogduk N, McGuirk B. An algorithm for precision diagnosis. In Bogduk N, McGuirk B (eds.) Medical Management of Acute and Chronic Low Back pain. An Evidence-Based Approach: Pain Research and Clinical Management, Vol. 13. Elsevier Science BV; Amsterdam, 2002, pp 177186.

6. Bogduk N. Low back pain. In Bogduk N (ed.) Clinical Anatomy of the Lumbar Spine and Sacrum, 3rd edition. Churchill Livingstone; New York, 1997, pp 187-214.

7. Bogduk N. International Spinal Injection Society guidelines for the performance of spinal injection procedures. Part 1: Zygapophyseal joint blocks. Clin J Pain 1997; 13:285-302.

8. Merskey H, Bogduk N. Classification of Chronic Pain: Descriptions of Chronic Pain Syndromes And Definitions Of Pain Terms. 2nd ed. IASP Press, Seattle, 1994, pp 180181.

9. Schwarzer AC, Aprill CN, Derby R et al. Clinical features of patients with pain stemming from the lumbar zygapophysi- al joints. Is the lumbar facet syndrome a clinical entity? Spine 1994, 19:1132-1137.

10. Schwarzer AC, Wang SC, Bogduk $\mathrm{N}$ et al. Prevalence and clinical features of lumbar zygapophysial joint pain: A study in an Australian population with chronic low back pain. Am Rheum Dis 1995, 54:100106.

11. Manchikanti L, Boswell MV, Singh V et al. Prevalence of facet joint pain in chronic spinal pain of cervical, thoracic, and lumbar regions. BMC Musculoskelet Disord 2004; 5:15.

12. Manchikanti L, Pampati V, Fellows B et al. The inability of the clinical picture to characterize pain from facet joints. Pain Physician 2000, 3:158-166.

13. Manchikanti L, Pampati V, Fellows B et al. The diagnostic validity and therapeutic value of medial branch blocks with or without adjuvants. Curr Rev Pain 2000, 4: 337-344.

14. Manchikanti L, Singh V, Pampati V et al. Evaluation of the relative contributions of various structures in chronic low back pain. Pain Physician 2001, 4:308-316.

15. Manchikanti L, Hirsch JA, Pampati V. Chronic low back pain of facet (zygapophysial) joint origin: Is there a difference based on involvement of single or multiple spinal regions? Pain Physician 2003, 6:399-405.

16. Manchikanti L, Singh V, Pampati V et al. Is there correlation of facet joint pain in lumbar and cervical spine? Pain Physician 2002, 5:365-371.

17. Manchikanti L, Staats PS, Singh V et al. Evidence-based practice guidelines for interventional techniques in the management of chronic spinal pain. Pain Physician 2003; 6:3-80.

18. Boswell MV, Singh V, Staats PS et al. Accuracy of precision diagnostic blocks in the diagnosis of chronic spinal pain of facet or zygapophysial joint origin. Pain Physician 2003; 6:449-456.

19. Dreyfuss P, Schwarzer AC, Lau P et al. Specificity of lumbar medial branch and $\mathrm{L}_{5}$ dorsal ramus blocks: A computed tomography study. Spine 1997; 22:895-902.

20. Kaplan M, Dreyfuss P, Halbrook B et al. The ability of lumbar medial branch blocks to anesthetize zygapophysial joint. Spine 1998; 23:1847-1852.

21. Schwarzer AC, Aprill CN, Derby R et al. The false-positive rate of uncontrolled diagnostic blocks of the lumbar zygapophysial joints. Pain 1994; 58:195-200.

22. Manchikanti L, Singh V, Pampati V. Are diagnostic lumbar medial branch blocks valid? Results of 2-year follow up. Pain Physician 2003; 6:147-153.

23. Saal JS. General principles of diagnostic testing as related to painful lumbar spine disorders. Spine 2002; 27:2538-2545.

24. Carragee E, Tanner C, Khurana S et al. The rates of false-positive lumbar discography in select patients without low back symptoms. Spine 2000; 25:1373-1381.

25. Carragee EJ, Alamin TF, Miller J et al. Provocative discography in volunteer subjects with mild persistent low back pain. Spine I 2002; 2:25-34.

26. Manchikanti L, Singh V, Pampati $V$ et al. Provocative discography in low back pain patients with or without somatization disorder: A randomized prospective evaluation. Pain Physician 2001; 4:227-239.

27. Manchikanti L, Pampati V, Fellows B et al. Influence of psychological factors on the ability of diagnose chronic low back pain of facet joint origin. Pain Physician 2001; 4:349-357.

28. Schwarzer AC, Derby R, Aprill CN et al. The value of the provocation response in lumbar zygapophysial joint injections. Clin J Pain 1994, 10:309-313. 
